\title{
Flame-retardant carbon nanotube films
}

\author{
Dawid Janas $^{\mathrm{a}, \mathrm{b},{ }^{*}, \text { Monika Rdest }}{ }^{\mathrm{a}}$, Krzysztof K.K. Koziol ${ }^{\mathrm{a}}$ \\ ${ }^{a}$ Department of Materials Science and Metallurgy, University of Cambridge, 27 Charles \\ Babbage Rd, CB3 OFS Cambridge, United Kingdom \\ ${ }^{b}$ Department of Chemistry, Silesian University of Technology, B. Krzywoustego 4, 44-100 \\ Gliwice, Poland
}

\begin{abstract}
We have demonstrated fire-retardancy properties of a polymer matrix-free CNT film for the first time. As compared with classical fire-retardant materials such as Kevlar, Twaron or Nomex, the CNT film showed a spectrum of advantages. The material is lightweight, flexible and well-adherent to even the most complicated shapes. The results have showed that by using CNTs for fire-retardancy we can extend the operational time almost two-fold, what makes CNTs a much better protection than the solutions employed nowadays. We believe that among other great properties of CNT, their macroscopic assemblies such as CNT films show significant potential for becoming a fire protective coating, which exhibits high performance in not sustaining fire.
\end{abstract}

Key words: Carbon nanotubes, Thin films, Flammability, Thermal management.

\section{Introduction}

Ever since carbon nanotubes (CNTs) have been put on the spotlight by Iijima's paper in 1991 [1], there has been a growing interest in exploiting their unique properties for a spectrum of applications. Due to their electrical [2, 3], thermal $[4,5]$, mechanical $[6,7]$ and optical $[8,9]$ characteristics they often outperform classical materials, when these properties of individual CNTs are translated from nano- to macro-scale. One often overlooked attribute of CNTs is their high stability in terms of corrosion [10] or exposure to elevated temperature [11]. What is a serious

\footnotetext{
${ }^{*}$ Corresponding author. Tel: + 4832 2372958. E-mail address: dawid.janas@ polsl.pl (D. Janas).
} 
difficulty for CNT functionalization (and thus integration with other materials) [12] becomes an asset when CNTs are employed as protection against these harsh conditions.

Flame-retardant materials are very important in everyday life. The ability to stop the fire from spreading can save lives when people are stuck on an airplane or inside a car/house/etc., from which they cannot escape. To tackle this problem, halogenated chemicals like TBBPA, PBDE, HBCD or TBPA are often added [13], but they release toxic gases during combustion such as organohalogens, hydrochloric and hydrobromic acid [13, 14], which are one of the leading causes of death in fire accidents. As an alternative, a range of phosphor-bearing (phosphates, phosphonates, phosphines, etc.) [15] or silicon-based (silicones, silicas, silicates, etc.) [16] compounds can be used. Additives from nanomaterials such as nanoclays [17] or CNTs [18] have proved to be successful replacements of conventional flame retardants. In particular, CNTs have been found very effective in this matter. CNTs (in most cases MWCNTs) have improved fire-retardancy of PE [19], LLDPE [20], PP [18, 21, 22], PMMA [23, 24], PP/PMMA [25], PS [26], PET [27], Nylon 6 [28], EVA [29, 30], PAA/PEI [31], modified-epoxy resin [32] and cotton [33]. CNT contents as low as $0.5 \%$ are already potent enough to significantly reduce the heat release rate [23]. However, to our best knowledge, none of the published studies focused on a scenario, in which CNT-based flame-retardant would not rely on CNTs dispersed in some sort of matrix having loading of a few weight percent.

In this paper, we examined how a free-standing CNT layer can be used for fire-retardancy. A CNT sheet was very effective in terms of stopping of fire from spreading as compared with traditionally used materials such as Nomex, Twaron, Kevlar, etc. We believe that a light, flexible and easy to produce from renewable sources layer of CNTs can already be a competitive solution for applications requiring fire-retardancy properties.

\section{Experimental}

\subsection{Materials}

Free-standing CNT sheets (thickness: $10 \mu \mathrm{m}$ ) were obtained by a method reported by us [34]. In brief, CNTs (Nanocyl NC7000, multi-wall, outer diameter $10 \pm 1 \mathrm{~nm}$ ), and ethyl cellulose were sonicated in isopropanol for 15 minutes. As obtained dispersion was loaded into a spray gun and deposited onto a polymer substrate $(15 \mathrm{x} 10.5 \mathrm{~cm}$, Kapton foil). Because of the low affinity of the as-made CNT sheet to the support, it could be easily peeled off 
creating a free-standing CNT layer. In the final step, surfactant was effectively removed by flash annealing in air leaving virtually no residue (ignited with a blowtorch for 2 seconds during which ethyl cellulose burns up).

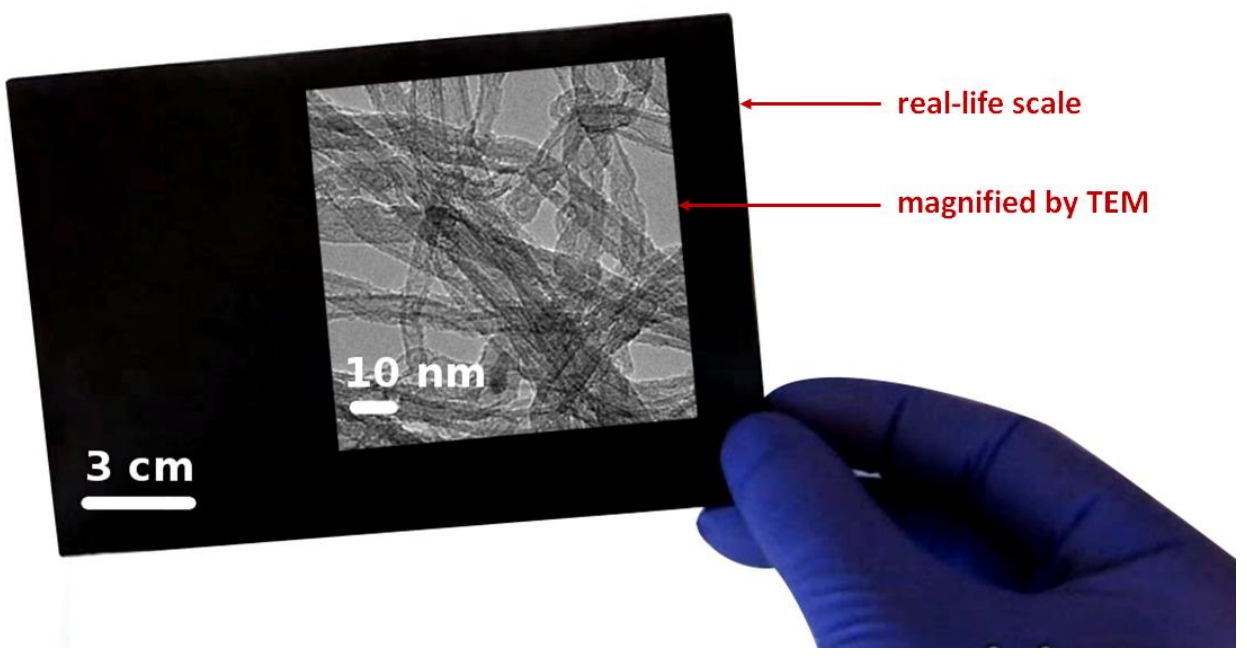

Fig. 1 Real-life scale image of the CNT film with TEM micrograph overlaid.

Such prepared CNT sheets (Fig. 1) were our main material for examination of fire retardancy properties of CNTs. In addition, we prepared a selection of reference materials - Twaron, Kevlar, Nomex, paper sprayed with CNTs (Nanocyl NC7000) from the front, both sides and clear paper - each having the same size. First three reference materials are aramids well-known for their fire-retardant properties. Paper-samples were used to evaluate the influence of CNTs.

\subsection{Flammability tests}

Specimens were mounted on a holder as shown in Fig. 2 Four clamps supported the samples during flaming to keep them from fluttering. The source of flame was put $75 \mathrm{~mm}$ away from the sample surface (the flame itself was touching the surface). In parallel, an IR camera (Flir T440) and DSLR (Nikon D3200) recorded visual image and information about the temperature. Moreover, an on-line pyrometer (Impac IPE140) measured the temperature of the hot-spot where the flame touched the sample. Once the flame was ignited, it was kept on until no more structural changes could be observed to the samples. Maximum and average temperature on the samples was recorded. 


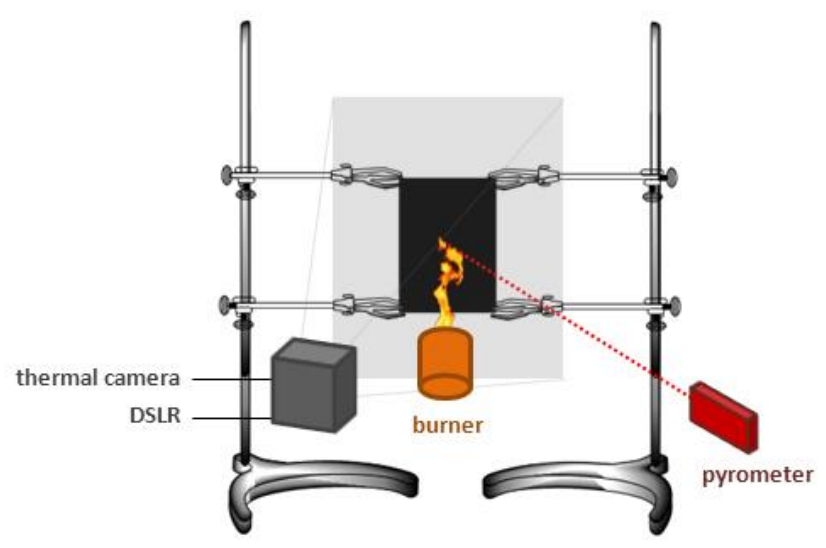

Fig. 2 Setup used for flammability tests.

\subsection{Characterization}

Micrographs of as made and flame-tested samples were taken to observe changes to the microstructure during the treatment. All CNT-free samples were sputtered (1 min, $25 \mathrm{~mA})$ with a thin layer of gold to make them conductive for imaging on Nova NanoSEM electron microscope. Having as made CNT material also enabled determination of the changes to the composition by means of EDX in the same Nova NanoSEM electron microscope coupled with Bruker QUANTAX 400 EDS spectrometer. TEM was obtained on Tecnai Osiris (200 keV). Finally, thermograms of the samples before burning were carried out to get insight into the thermal stability and mechanism of thermal decomposition. In each run, $5 \mathrm{mg}$ of sample was burned in air flow $(50 \mathrm{~mL} / \mathrm{min})$ from room temperature up to $1,000^{\circ} \mathrm{C}$ at a rate of $10^{\circ} \mathrm{C} / \mathrm{min}$ (Mettler Toledo).

\section{Results and discussion}

\subsection{Thermal properties and composition}

First, to establish thermal stability of the materials selected for this study, a TGA analysis was performed. The results revealed that the free-standing CNT film is the most stable material in air at high-temperature having the maximum rate of decomposition at $610^{\circ} \mathrm{C}$ (Fig. 3a). Nomex, Kevlar and Twaron, had the maximum rate of decomposition at slightly lower temperatures i.e. about $601^{\circ} \mathrm{C}, 583^{\circ} \mathrm{C}$ and $567^{\circ} \mathrm{C}$, respectively. As expected, much lower decomposition temperature regime was shown by neat paper and paper covered with CNTs. After burning, we 
noted the amount of residue left: Twaron (5.5\%wt), Kevlar (3.9\%wt), Nomex (2.0\%), clear paper (17.8\%wt), paper sprayed with CNTs from both sides (13.0\%wt) and free-standing CNT film (14.1\%wt).

(a)

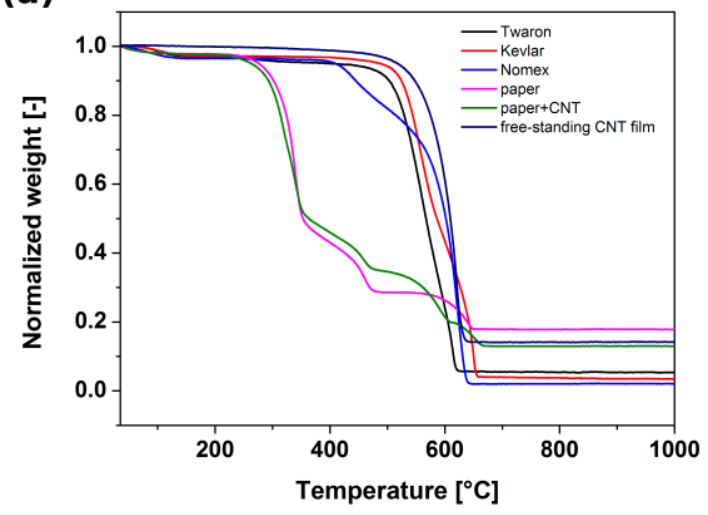

(b)

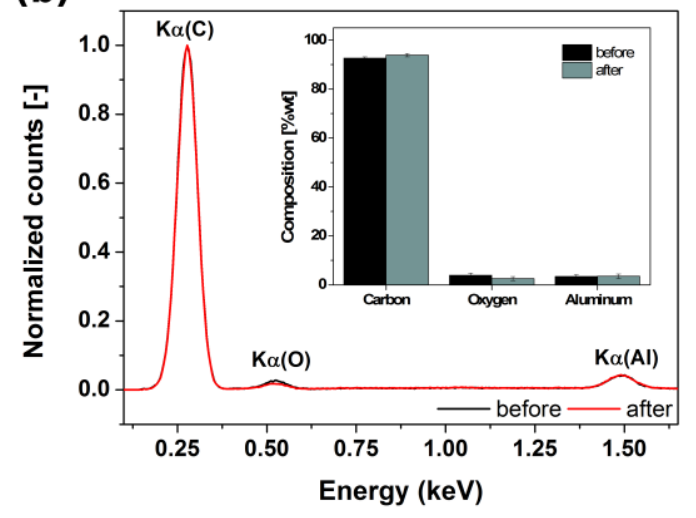

Fig. 3 (a) thermograms of the samples in the flow of air, (b) EDX spectra of a free-standing CNT film before and after flammability test. The inset shows the content in \%wt. of carbon, oxygen and aluminum in the samples.

In parallel, the composition of the CNT material before and after initial flammability tests was evaluated by EDX (Fig. 3b). The results show that the material almost does not change during one minute exposure to flame. Although we could expect oxidation at this elevated temperature, exposure was not long enough for the material to deteriorate. In fact what we observed was slight purification of the material because the amount of oxygen decreased, what increased the relative content of carbon. The most defective CNTs and impurities from the synthesis are commonly rich in oxygen, but less thermally stable. As a consequence, the exposure to high temperature can remove them and leave the CNTs having the best crystallization intact (if the exposure to oxygen at high temperature is short enough). It encouraged us to run a thorough flammability study of CNTs with the already mentioned materials as references.

\subsection{Fire-retardant properties}

Fig. 4a shows the temperature recorded at the point where the flame met the surface of the sample. It can be seen that in all the cases it is about $900^{\circ} \mathrm{C}$. Variation in the temperature could be attributed to the evolution of heat from the burned surface. As such temperature, the flame is of sufficiently high temperature to initiate exothermic decomposition of some of the compounds present in the material. When there is more contribution from such processes, the temperature recorded on the surface is higher and vice versa. 
(a)

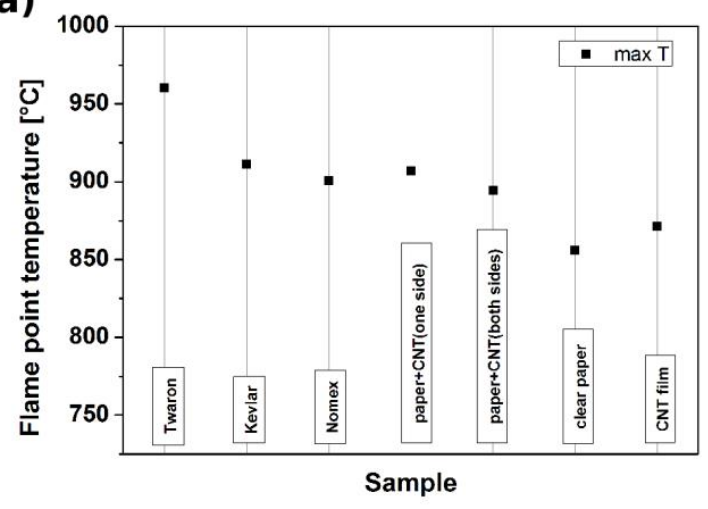

\section{(b)}

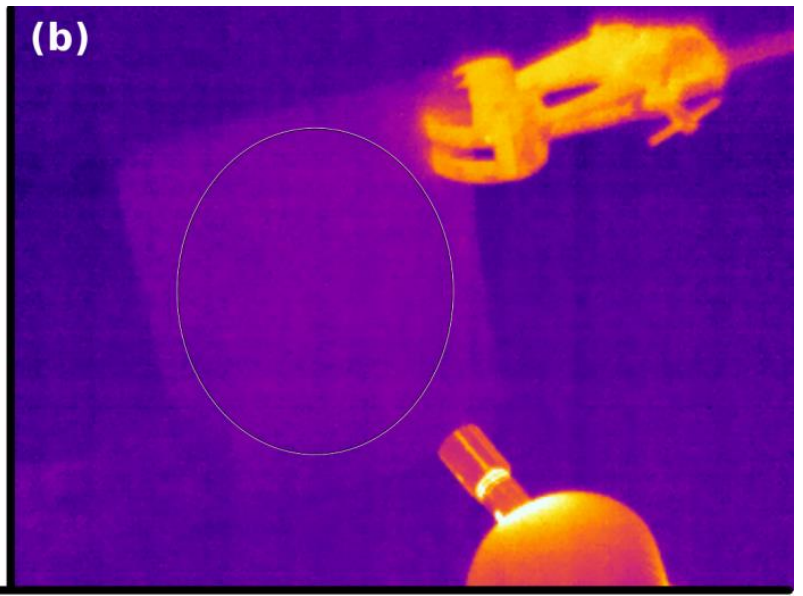

\section{(c)}

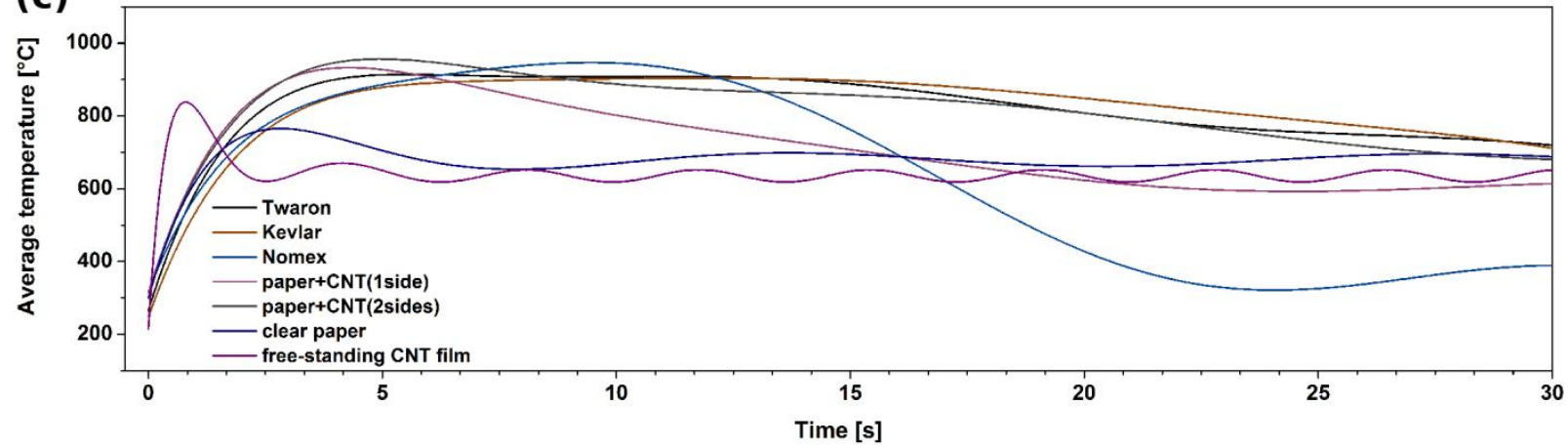

Fig. 4 (a) maximum temperature recorded by pyrometer at the point where the flame touched the sample, (b) an example of recording average temperature within the ellipse, (c) average temperature during the course of flaming.

As expected, the least stable among the samples was the one made purely of paper. It burned rapidly leaving just ash. Covering the paper with CNTs however, helped to slow down spreading of fire. The integrity was preserved despite the fact that after 20 seconds paper was ignited by fire and then consumed. Furthermore, after just 5 seconds of exposure of flame to Nomex, a hole was burned in the place of contact, which grew larger as the time passed. After 30 seconds, the hole stopped growing, but having it in the material directly reflected on the average recorded temperature in the selected area, which was lower because it accounted for the background where the hole was formed (Fig. 4c). In the case of Kevlar, a hole also formed, but after 15 seconds. It was much smaller than in the case of Nomex showing better fire-retardancy properties of this type of aramid. Twaron has shown almost exactly the same behavior as Kevlar, its para-aramid relative. Finally, in the case of a CNT film, we observed an excellent fire-retardancy performance and the fire managed to burn a hole through the film only after 25 seconds. This is a significant improvement to the results obtained in the case of aramids, wherein the same effect was observed in half the time or less. Similarly, once the source of fire is turned off, the fire is extinguished immediately. 


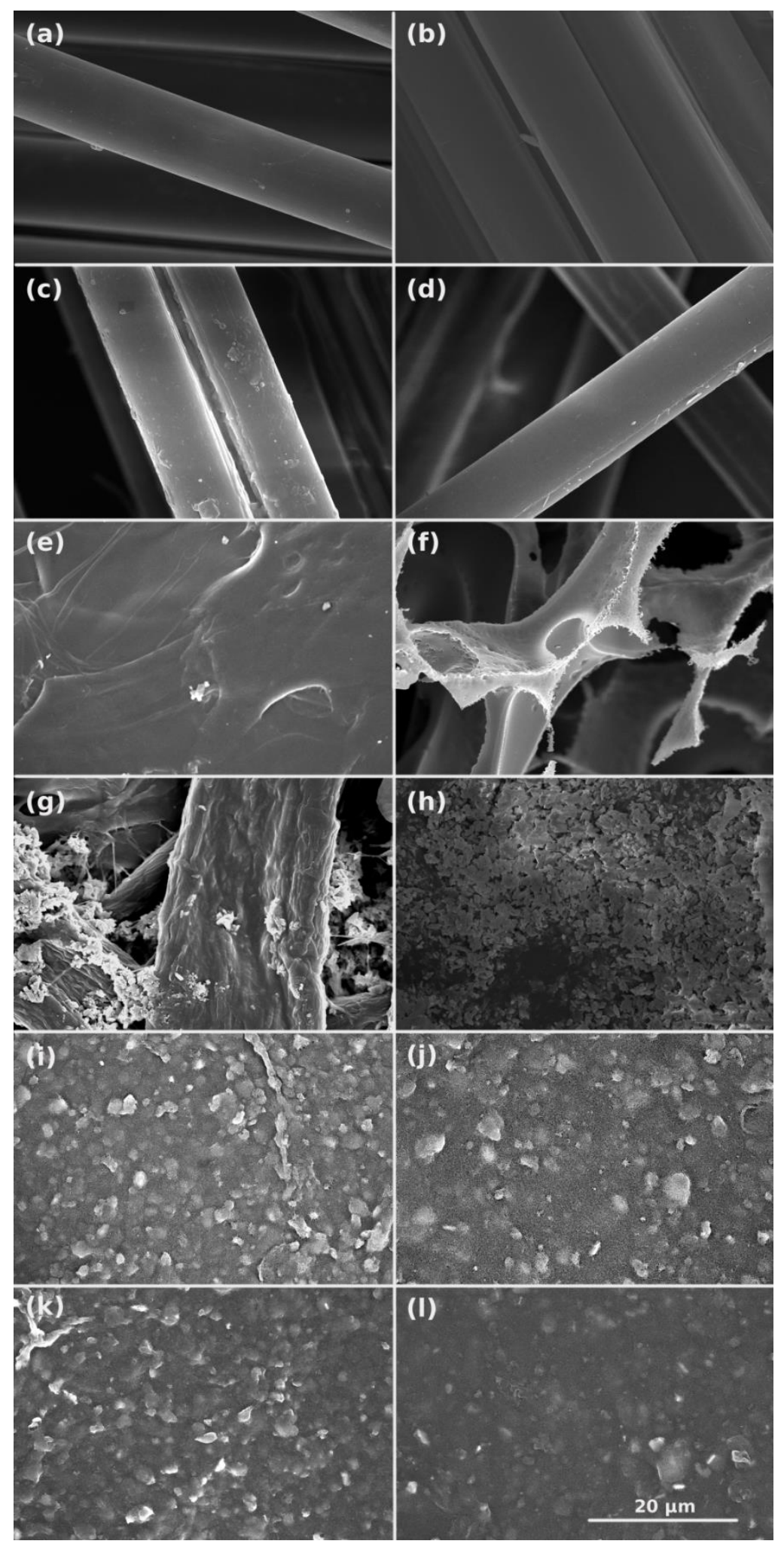

Fig. 5 SEM micrographs of Kevlar, Twaron, Nomex, paper, paper covered with CNTs and free-standing CNT film before (a,c,e,g,i,k) and after (b,d,f,h,j,l) flammability tests, respectively. 


\subsection{Microstructures}

Although all three aramids have relatively similar structure, Kevlar and Twaron look relatively unaffected by the flames, but Nomex appears degraded (Fig. 5). As anticipated, the microstructure of paper after burning looks much different because it essentially represents ash. Finally, CNT surface looks almost untouched. In fact, the material appears slightly purified from contamination, what explains a small decrease in $\mathrm{O}_{2}$ content in EDX (Fig. 3b). All visual images between and after flammability tests can be found in the Table S1 (Supplementary file).

\subsection{Conclusions}

In summary, we examined how CNT films (and selected reference materials - Kevlar, Twaron, Nomex) help to stop fire from spreading. CNT sheets as compared with these materials were found to have better fire-retardant properties. Free-standing CNT sheets have shown big potential because they could actually be woven into fabric (due to their suitable mechanical properties [34]) to create fire-resistant garment for fire fighters and other people exposed to flammable conditions. Moreover CNT sheets are free of halogen atoms (as some of the flame-retardant materials), which makes them much safer because their combustion does not produce toxic fumes (the primary cause of death). Finally, we believe that their flexible and lightweight nature could make this solution advantageous in many branches of life. Since they are durable and do not introduce excessive weight we can imagine them as parts of fire-protection systems for aircrafts, cars and other vehicles.

\section{Acknowledgements}

D.J., M.R. and K.K. acknowledge the European Research Council (under the Horizon 2020 Program, ERC grant agreement 641382) and the Royal Society for the financial support. D.J. would also like to thank National Science Center, Poland (under the Polonez program, grant agreement UMO-2015/19/P/ST5/03799) and the European Union's Horizon 2020 research and innovation programme (Marie Skłodowska-Curie grant agreement 665778).

\section{References}

[1] S. Iijima, Helical microtubules of graphitic carbon, Nature, 354 (1991) 56-58.

[2] S. Hong, S. Myung, Nanotube electronics: a flexible approach to mobility, Nature nanotechnology, 2 (2007) 207-208.

[3] D. Janas, A.P. Herman, S. Boncel, K.K.K. Koziol, Iodine monochloride as a powerful enhancer of electrical conductivity of carbon nanotube wires, Carbon, 73 (2014) 225-233.

[4] E. Pop, D. Mann, Q. Wang, K. Goodson, H. Dai, Thermal conductance of an individual single-wall carbon nanotube above room temperature, Nano Lett, 6 (2006) 96-100.

[5] E.T. Thostenson, C. Li, T.-W. Chou, Nanocomposites in context, Composites Science and Technology, 65 (2005) 491-516. 
[6] M.F. Yu, O. Lourie, M.J. Dyer, K. Moloni, T.F. Kelly, R.S. Ruoff, Strength and breaking mechanism of multiwalled carbon nanotubes under tensile load, Science, 287 (2000) 637-640.

[7] B.G. Demczyk, Y.M. Wang, J. Cumings, M. Hetman, W. Han, A. Zettl, R.O. Ritchie, Direct mechanical measurement of the tensile strength and elastic modulus of multiwalled carbon nanotubes, Materials Science and Engineering: A, 334 (2002) 173-178.

[8] C. Fantini, A. Jorio, M. Souza, M.S. Strano, M.S. Dresselhaus, M.A. Pimenta, Optical transition energies for carbon nanotubes from resonant Raman spectroscopy: environment and temperature effects, Phys Rev Lett, 93 (2004) 147406.

[9] D. Janas, N. Czechowski, B. Krajnik, S. Mackowski, K.K. Koziol, Electroluminescence from carbon nanotube films resistively heated in air, Applied Physics Letters, 102 (2013) 181104.

[10] D. Janas, A.C. Vilatela, K.K.K. Koziol, Performance of carbon nanotube wires in extreme conditions, Carbon, 62 (2013) 438-446.

[11] D. Janas, A. Cabrero-Vilatela, J. Bulmer, L. Kurzepa, K.K. Koziol, Carbon nanotube wires for hightemperature performance, Carbon, 64 (2013) 305-314.

[12] P.-C. Ma, N.A. Siddiqui, G. Marom, J.-K. Kim, Dispersion and functionalization of carbon nanotubes

for polymer-based nanocomposites: A review, Composites Part A: Applied Science and Manufacturing, 41

(2010) 1345-1367.

[13] F. Laoutid, L. Bonnaud, M. Alexandre, J.M. Lopez-Cuesta, P. Dubois, New prospects in flame retardant polymer materials: From fundamentals to nanocomposites, Materials Science and Engineering: R: Reports, 63 (2009) 100-125.

[14] S.D. Shaw, A. Blum, R. Weber, K. Kannan, D. Rich, D. Lucas, C.P. Koshland, D. Dobraca, S. Hanson, L.S. Birnbaum, Halogenated flame retardants: do the fire safety benefits justify the risks?, Reviews on environmental health, 25 (2010) 261-305.

[15] I. van der Veen, J. de Boer, Phosphorus flame retardants: properties, production, environmental occurrence, toxicity and analysis, Chemosphere, 88 (2012) 1119-1153.

[16] S. Hamdani, C. Longuet, D. Perrin, J.-M. Lopez-cuesta, F. Ganachaud, Flame retardancy of siliconebased materials, Polymer Degradation and Stability, 94 (2009) 465-495.

[17] C. Kaynak, H.O. Gunduz, N.A. Isitman, Use of Nanoclay as an Environmentally Friendly Flame Retardant Synergist in Polyamide-6, Journal of Nanoscience and Nanotechnology, 10 (2010) 7374-7377.

[18] T. Kashiwagi, E. Grulke, J. Hilding, R. Harris, W. Awad, J. Douglas, Thermal Degradation and Flammability Properties of Poly(propylene)/Carbon Nanotube Composites, Macromolecular Rapid Communications, 23 (2002) 761-765.

[19] G. Beyer, Filler blend of carbon nanotubes and organoclays with improved char as a new flame retardant system for polymers and cable applications, Fire and Materials, 29 (2005) 61-69.

[20] S. Bocchini, A. Frache, G. Camino, M. Claes, Polyethylene thermal oxidative stabilisation in carbon nanotubes based nanocomposites, European Polymer Journal, 43 (2007) 3222-3235.

[21] T. Kashiwagi, E. Grulke, J. Hilding, K. Groth, R. Harris, K. Butler, J. Shields, S. Kharchenko, J.

Douglas, Thermal and flammability properties of polypropylene/carbon nanotube nanocomposites, Polymer, 45 (2004) 4227-4239.

[22] T. Tang, X. Chen, H. Chen, X. Meng, Z. Jiang, W. Bi, Catalyzing Carbonization of Polypropylene Itself by Supported Nickel Catalyst during Combustion of Polypropylene/Clay Nanocomposite for Improving Fire Retardancy, Chemistry of Materials, 17 (2005) 2799-2802.

[23] T. Kashiwagi, F. Du, K.I. Winey, K.M. Groth, J.R. Shields, S.P. Bellayer, H. Kim, J.F. Douglas, Flammability properties of polymer nanocomposites with single-walled carbon nanotubes: effects of nanotube dispersion and concentration, Polymer, 46 (2005) 471-481.

[24] T. Kashiwagi, F. Du, J.F. Douglas, K.I. Winey, R.H. Harris, J.R. Shields, Nanoparticle networks reduce the flammability of polymer nanocomposites, Nat Mater, 4 (2005) 928-933.

[25] P.a. Song, L. Xu, Z. Guo, Y. Zhang, Z. Fang, Flame-retardant-wrapped carbon nanotubes for simultaneously improving the flame retardancy and mechanical properties of polypropylene, Journal of Materials Chemistry, 18 (2008) 5083-5091.

[26] B.H. Cipiriano, T. Kashiwagi, S.R. Raghavan, Y. Yang, E.A. Grulke, K. Yamamoto, J.R. Shields, J.F. Douglas, Effects of aspect ratio of MWNT on the flammability properties of polymer nanocomposites, Polymer, 48 (2007) 6086-6096. 
[27] Z. Wu, M. Xue, H. Wang, X. Tian, X. Ding, K. Zheng, P. Cui, Electrical and flame-retardant properties of carbon nanotube/poly(ethylene terephthalate) composites containing bisphenol A bis(diphenyl phosphate), Polymer, 54 (2013) 3334-3340.

[28] B. Schartel, P. Pötschke, U. Knoll, M. Abdel-Goad, Fire behaviour of polyamide 6/multiwall carbon nanotube nanocomposites, European Polymer Journal, 41 (2005) 1061-1070.

[29] G. Beyer, Short communication: Carbon nanotubes as flame retardants for polymers, Fire and Materials, 26 (2002) 291-293.

[30] F. Gao, G. Beyer, Q. Yuan, A mechanistic study of fire retardancy of carbon nanotube/ethylene vinyl acetate copolymers and their clay composites, Polymer Degradation and Stability, 89 (2005) 559-564.

[31] Y.S. Kim, R. Davis, Multi-walled carbon nanotube layer-by-layer coatings with a trilayer structure to reduce foam flammability, Thin Solid Films, 550 (2014) 184-189.

[32] C.-F. Kuan, W.-J. Chen, Y.-L. Li, C.-H. Chen, H.-C. Kuan, C.-L. Chiang, Flame retardance and thermal stability of carbon nanotube epoxy composite prepared from sol-gel method, Journal of Physics and Chemistry of Solids, 71 (2010) 539-543.

[33] K. Bharathi Yazhini, H. Gurumallesh Prabu, Study on flame-retardant and UV-protection properties of cotton fabric functionalized with ppy-ZnO-CNT nanocomposite, RSC Advances, 5 (2015) 49062-49069.

[34] D. Janas, M. Rdest, K. Koziol, Free-standing films from chirality-controlled carbon nanotubes, Materials \& Design, (in press) (2017). 